Arab World English Journal (June 2019)

Theses ID 234

Pp. $1-90$

DOI: https://dx.doi.org/10.24093/awej/th.234

\title{
An Application of Vinay and Darbelnet's Translation Model to the English Translation of Ghassan Kanafani's Novel Men in the Sun: A Descriptive Analytical Study
}

\author{
Sarah I. Alqunaibet \\ Department of English Language and Literature \\ College of Languages and Translation \\ Al Imam Muhammad Ibn Saud Islamic University, Saudi Arabia
}

Author: Sarah I. Alqunaibet

Thesis Title: An Application of Vinay and Darbelnet's Translation Model to the English

Translation of Ghassan Kanafani's Novel Men in the Sun: A Descriptive Analytical Study

Subject/major: Translation

Institution: Al-Imam Mohammad Ibn Saud Islamic University, College of Languages and

Translation, Saudi Arabia.

Degree: MA in Translation

Year of award: 2018

Supervisor: Dr. Kholood Alakawi

Key Words: Translation strategies, Vinay and Darbelnet's model, direct translation, oblique translation, Men in the Sun.

\section{Abstract}

The present study aimed at exploring Vinay and Darbelnet's translation model in the translation of Ghassan Kanafani's novel Men in the Sun from Arabic to English. The main objectives of this study were to identify the most common strategies adopted by the translator of the novel according to Vinay and Darbelnet's model, to explore the basic problems found in the translation of the novel and to examine the strategies applied by the translator to solve the translation problems according to Vinay and Drabelnet's translation model. For the purpose of this study, a descriptive analytical methodology was carried out on the first two chapters of the novel. The findings revealed that the most frequent strategies were literal translation followed by transposition and modulation according to the model. The findings also revealed two types of translation problems, linguistic problems including lexical and syntactic problems, and cultural problems including cultural expressions and cultural bound terms. Some strategies according to that model were applied to overcome translation problems including transposition, modulation and equivalence. However, some translation problems were solved by strategies that were not described by the model. More comprehensive models were recommended to be adopted in further studies in literature translation. 
Cite as: Alqunaibet, S.I. (2018). An Application of Vinay and Darbelnet's Translation Model to the English Translation of Ghassan Kanafani's Novel Men in the Sun: A Descriptive Analytical Study. Al-Imam Mohammad Ibn Saud Islamic University, College of Languages and

Translation, Saudi Arabia. (Master Thesis). Retrieved from Arab World English Journal (ID

Number: 234. June, 2019, 1-90. DOI: https://dx.doi.org/10.24093/awej/th.234 